DOI: $10.15503 /$ jecs20162.11.19

\title{
IN SEARCHING FOR SCIENCE UNDERSTANDING. APPLYING THE SOCIOLOGY OF A SCIENCE BASED APPROACH
}

\author{
DOROTA JEDLIKOWSKA
}

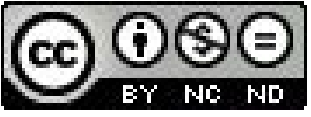

\author{
Faculty of Philosophy, Jagiellonian University \\ Gołębia Street 24, 31-007, Kraków, Poland \\ E-mail address: d.jedlikowska@gmail.com
}

\begin{abstract}
The paper discusses the chosen ongoing perspectives related to science understanding based problems. Science is viewed, following Robert Merton, as a functioning institution. Social context plays a significant role in defining the possibilities of developing science. The question arises how a functioning institution can be effectively analyzed and which perspectives can be implemented. Hence this paper's goal is to reveal some ways of exploring science understanding. Consequently the paper touches the scientific discourses upon science discussing its academic functional ethos and on the other hand tension between bureaucratization and openness in science. More broadly how far science is democratized in an academic interaction.

The proposition of examining the problem of the quality of science as an institution is to grasp two perspectives: first, the formal perspective, related to the legal field and its rationality and second, followed by Adele Clarke known as "situatedness". The idea of joining formalization with situatedness can be regarded as an embodiment within John Meyer and Brian Rowan's concept of an institutionalized organization. Hence science understanding is defined as a complex functioning institution escaping from a modern version of science into many postmodern ad-hoc made sciences.

The paper's intention is to provide problems and proposition of solving them through applying an integrating perspective.
\end{abstract}

Key words: science understanding, sociology of science, science policy, formalization, situatedness, rationality

\section{INTRODUCTION}

The debate upon science understanding dates back to the middle of the $20^{\text {th }}$ century regarding concerns made by the sociology of science upon science performing models. Science understanding has captured various models concerning criteria as follows: strategy, participants in decision making, participants in science, evaluation and control. The general tendency is going from early linear/technocratic models in understanding science where priority is 
given to scientists and science was viewed as a certain point of reference also to policy. From this stream models of science application/utilitarianism started to appear highlighting the necessity of science usage to be widely socially spread. Hence the science audience including different types of stakeholders has begun to be more and more diverse. The latest models have taken into account democratic values in making science and engaging non-scientific and knowledgeable participants into scientific projects and results. Currently science is not an exclusive arena reserved only for scientists but it is called an open science where extended dialogue with a wide audience is promoted as a form of good practice. The key directions in open science based models are developing a feeling of friendliness in making contacts and using scientific platforms and tools, strengthening the cooperation and synergy between various groups of scientists, being focused on non-scientific participants to for instance formulate results in the language understood for a wide public, providing data with open access and concentrating efforts on contributing to society in largely measurable ways including extended reviewing consultations (Logar, 2011; Fecher, Friesike, 2014; Valente, Castellani, Larsen, Aro,2014; compare Jedlikowska, 2015).

The paper's assumption is not to claim that models of science are progressing. Theoretically new models are being appearing but practically science is involved in many traditions and scopes of interactions with other scientists. Moreover different roles are assigned to scientists and within the academic community there are plenty of modes of making and communicating science (Goban-Klas, 1999). It is an open question and research has to be done to recognize which models are dominant at the same time coexisting with more technocratic models. The importance of science understanding is significant to grasp a better understanding of scientific culture of a particular region, country or within the European Union. Shaping science policy has an enormous impact on intellectual and scientific capital building processes where the ethos of science must be valued and maintained on a daily basis. These reflections find their reference platform within the sociology of science where science is perceived as a functioning institution (Merton, 1973).

On the following pages the chosen items will be discussed to provide first of all an overview upon scientific discourses regarding science functionality and tension between its bureaucracy and openness in relation to processes of democratizing science. At this point the main tendencies within science policy will be given as well. Secondly the chapter suggesting combining contrary reflections like formalization and situatedness of Adele Clarke will be formulated to show a methodological potential in discovering science understanding. It is worth mentioning here that methodology of grounded theory is almost unmet in papers about science especially in the Polish arena. Thirdly the theory proposition will be illustrated to obtain a holistic attitude in building understanding about science as an institution. In this context John Meyer and Brian Rowan's theory of institutionalized organization is regar- 
ded as of high potential to discuss the concept of rationality of science and functioning in science.

\section{SCIENTIFIC DISCOURSES ABOUT SCIENCE FUNCTIONING}

"Science is a deceptively inclusive word which refers to a variety of distinct though interrelated items. It is commonly used to denote (1) a set of characteristic methods by means of which knowledge is certified; (2) a stock of accumulated knowledge stemming from the application of these methods; (3) a set of cultural values and mores governing the activities termed scientific; or (4) any combination of the foregoing (...) The ethos of science is that affectively toned complex of values and norms which is held to be binding on the man of science. The norms are expressed in the form of prescriptions, proscriptions, preferences and permissions. They are legitimized in terms of institutional values (...) There is the further question of the ratio of scientific achievement to scientific potentialities. Science develops in various social structures, to be sure, but which provide an institutional context for the fullest measure of development? The institutional goal of science is the extension of certified knowledge. The technical methods employed toward this end provide the relevant definition of knowledge: empirically confirmed and logically consistent statements of regularities (which are, in effect, predictions). The institutional imperatives (mores) derive from the goal and the methods. The entire structure of technical and moral norms implements the final objective. The technical norm of empirical evidence, adequate and reliable, is a prerequisite for sustained true prediction; the technical norm of logical consistency, a prerequisite for systematic and valid prediction. The mores of science possess a methodologic rationale but they are binding, not only because they are procedurally efficient, but because they are believed right and good. They are moral as well as technical prescriptions" (Merton, 1973, pp. 268-270).

Sociology of science is recognized as an institutionally based knowledge aiming at figuring out social structures evaluating within science, institutional mores which are believed to be unreplaceable and worth being followed, set of methods and standards which can only make a progress in discovering reality and maintenance of a particular set of values which are being considered as scientific. Scientific knowledge arises from conducting and demonstrating specific goals and methods which guarantee pursuing science so in consequence such a type of knowledge is being certified and cultivated. Hence science is rooted in institutional/cultural contexts - being defined as correct. The developed system of structures within science is a presumption of making knowledge institutionalized. The range of scientific bodies/agendas can demonstrate considerably different approaches in recognizing scientific knowledge or following assumed goals of a particular scientific policy system. The aim of the sociology of science is to discover the variety of inter- 
related aspects of social/cultural/institutional scientific reality which make a difference in shaping science. The impact of the sociology of science can be seen both in developing theories and in methods to catch a more up to date, diverse and holistic view of the processes which structuralize and institutionalize science. Science functioning depends on how science is understood and defined in particular, daily steps making science governed and institutionalized. It is a reason why discovering how science understanding is being settled and maintained is so crucial to increase awareness about the culture of making science.

Giving an example of values/ethos in science Piotr Sztompka, based on the Mertonian input to the sociology of science, provides us with the significant directions towards how contemporary so called Western science is being developed. P. Sztompka, following John Ziman, makes a division into academic and post-academic science. The core values of academic science are contemporarily biased. The key ones are as follows: universalism which refers to applying impersonal criteria in assessing scientifically made knowledge, communism (communalism) which means that science is a shared and that it should not be kept or considered privately - it also implies a free and unlimited communication about science and distribution of the results, disinterestedness which forbids being directed and empowered by individual motives because this bias makes pure curiosity and scientific passion unable to flourish, and organized skepticism in showing a suspicion and providing questions towards scientific results, also called public criticism (Merton, 1973, pp. 270-278; Sztompka, 2007).

These values are assigned to the academic (classical) way of making science. Today's perspective in science is treated as post-academic science which is first of all lacking trust. The lack of trust is interconnected with no searching for excellence in reviewing science. This is a consequence of "fiscalization of science" (relying on external financial agencies, searching for financial resources, applying more consumer based approach), "privatization of science" (increasing of sponsoring organizations and institutions whose criteria of evaluation are not always transparent), "commodification of science" (strong emphasis put on measurable and financial value with pressure of time combined with the reduction of fees), "bureaucratization of science" (requirement of planning and reporting for various actors), "diminishing exclusiveness and autonomy of the scientific community" (through extended networks of interested actors favoring sometimes contradictory motives and interests). Hence science as an institution is vulnerable to several threats when it comes to serving reliable, significant output and holding status of an independent and trustworthy institution. P. Sztompka specifies the five tensions: "transparency vs secrecy" which disturbs the criterion of communalism being addressed to open communication (transparency within science is strongly desirable to make known the entire process of obtaining scientific knowledge), "normative coherence vs anomie" refers to the need of widely recognized ways of making science stand against particularism and 
being driven by unrelated interests, "accountability vs arbitrariness" with a reference towards maintaining an organized skepticism and developing impersonal approach in evaluating scientific results (this direction postulates a wide range of self-reviewing policies and knowledge based requirements), "familiarity vs strangeness" addresses a standardized form of academic community which also makes it an exclusive community in comparison to other communities (unique character and style of scientific society), "rich networks (social capital) vs atomization" makes a clear viewing science also as a "collective enterprise" of strong social ties and system of collaboration with a specification of "visible colleges", "invisible colleges" and "virtual colleges" (Sztompka, 2007, pp. 216-219).

The challenge in this regard is to adjust Mertonian demands of academic science to a new reality in which science finds itself. "Mertonian principles, reconstituted in some new form fitting the new situation of science, can still provide a standard against which 'post-academic' science - more globalized, more industrialized, more bureaucratized, more politicized, more transdisciplinary, more dependent on funding - should be measured and made accountable. Only on this condition can trust in science - equally indispensable both for academic and post-academic science - be restored" (Ibidem, p. 219).

Another way of presenting science is given by John Turnpenny, Mavis Jones and Irene Lorenzoni who follow works of Silvio Funtowicz and Jerome Ravetz, although the core assumption of the lack of trust remains problematic - it is being replaced with the notion of quality. They propose discussing science as normal and post-normal science. "Normal science emphasizes trust in the inviolability of its objective representation of facts about nature, whereas PNS emphasizes quality (in the completeness of information, assessed by a range of epistemological and ontological positions). The quality control function of the extended peer community does not necessarily operate according to conventional scientific criteria, which rely heavily on quantitative assessment and on falsifiability (...) EPCs assessing the quality of policy proposals on the basis of their own knowledge, which includes cultural and moral perspectives" (Turnpenny, Jones, Lorenzoni, 2011, p. 292).

So called normal science is being prescribed, following Steve Fulle$r^{\prime}$ s paper, by the drive of "self-determining form of enquiry". The normal science is being contrasted with post-normal science where science is treated as "a social investment", steered by the demands of industrialization. Science is also viewed as a "shoddy science" which means that science: "underpinned by battles for budgets and grants where the quality of academic writing was (is - added by the paper's author) subservient to attainment of funding and personal promotion (...) these applications and perspectives ultimately lead to a science in which knowledge is used in an "atomic" way, incapable of understanding the bigger picture in planning for the future, and therefore to an obsolete science" (Ibidem, p. 290). 
To move further the reflection upon transparency in decision making processes, quality of science and making science progressed towards an openness, it is worth recalling two ideas provided by Angela Liberatore and Silvio Funtowicz. There are as follows: "democratizing expertise" and "expertising democracy". Both are defined as a participatory based approach to science against privatization of science governance. Both of them make a step ahead towards more transparency within post-normal/academic science. The problems with lack of sufficient quality and trust can stem from for instance not enough democratized institution of science. These conceptions undertake the problem of functioning democracy within science as an institution. In another words problems with democracy can affect greatly the trustworthiness and/or quality of science making privileged perspectives dominant and at the same time exclude others - less popular, less "scientific", consequently standing against classical scientific ethos.

The conceptions of "democratizing expertise" and "expertising democracy" are understood as: "enabling the 'tracking' of how decisions are made, by whom, on what basis - something that clearly also concerns the role of expertise. One can argue that there has been a short cut in moving from safeguarding due to tracking how decisions are made: is there an intermediate step of monitoring the process? (...) is it possible to find out what elements they provide to formulate and implement policy decisions, and how these elements are actually used. At the same time 'expertising democracy', that is, providing pluralistic expert advice to democratic institutions and to the citizenry more broadly, can be seen as a way of allowing for informed debate and bargaining, and increasing the capacity of democratic institutions to discuss and eventually meet citizens' expectations" (Liberatore, Funtowicz, 2003, p. 147).

The first notion refers to procedures which can secure safeguarding processes also through acceptance the right of broader audience for science participation and the second one emphasizes the social satisfaction and fulfillment of assumed results coming from scientific expertise. This tension is crucial for science understanding especially in a democratic society. Regarding democratic values and promoted models of science openness for instance the postulated values of exclusiveness of science and scientists as experts including disinterestedness can seem to be problematic to achieve, also including a question who is capable to monitor decision making processes and public can be considered intellectually interested and prepared for it? On the other hand public inclusiveness can stand against world colonization by experts. These are just examples of potential doubts and contrasts with theoretical models of science and valued participatory governance (Durant 2011). 


\section{INSTEAD OF A CONCLUSION: COMBINING PERSPECTIVES OF FORMALIZATION AND SITUATEDNESS - TOWARDS INVESTI- GATING AN INSTITUTIONALIZED ORGANIZATIONS IN MA- KING RESEARCH UPON SCIENCE}

In the context of discovering science understanding a fruitful proposition can be making a reference towards two approaches being inspired by Meyer and Rowan's contribution to sociological theory. All models of science constitute an assumed formalization of science which have been expressed in discourses about science functioning. Formalization provides a variety of components, differentiation of science construction where general criteria can be implemented into a particular research (Berger, 2000, p. 485). Giving a form of the researched reality is to expose collected data in framing the picture of science. This methodological attitude is found in the approach based on so called "situatedness" formulated by Adele Clarke (Clarke, 2003; Cisbani, 2010; Kacperczyk, 2007). Formalization which arises from situational maps can embrace the complexities of discoursive constructs. Methodology of situatedness reflects a post-modern turn and is going towards challenges regarding research of a post-reality especially in the context of lack of trust and quality in science. Situatedness refers to more chaotically defined reality to reveal a lack of consistency within the investigated area of research, which is characterized by specificity, contingency, ad-hoc decisions, and uncertainty. "If modernism emphasized universality, generalization, simplification, permanence, stability, wholeness, rationality, regularity, homogeneity, and sufficiency, then postmodernism has shifted emphases to localities, partialities, positionalities, complications, tenuousness, instabilities, irregularities, contradictions, heterogeneities, situatedness, and fragmentation - complexities" (Clarke 2003, p. 555).

To reconstruct, as in this case, science understanding which is a form of post-science of uncertain quality a researcher has to have an internalized holistic attempt without closing itself in the frame of a singular theory. If current science is lacking both trust and quality then the time is coming to explore irregularities and situatedness of science which is no longer perceived as stable, reliable and certain. In this context Mertonian values are being biased and thanks to Clarke's situatedness it is possible to provide a greater and more insightful look at processes which determine science. This holistic methodological view finds its confirmation in Mayer and Rowan's perspective of institutionalized organization which in the process of conducting research with this referential point can bring also a fresh overview to diagnose an institutional context of science. If we assume that institutions are uncertain then their rules are also to be questioned. If formal structures come from researched goals and methods (like in Merton's assumption) to provide an institutionally certified type of knowledge then ceremonial structures are only temporary, its legitimacy is made on an ad-hoc basis due to the need of a particular scholarship/agenda/source of investment. What makes science 
functioning more problematic is a presumption that formal structures do not necessarily functional to be a consequence of postulated goals but they can be an answer related to science environment. Ceremonial activity only cultivates myths that science is what we believe, "trust" it is science. "Formal structures of many organizations in the postindustrial society dramatically reflect the myths of their institutional environments instead of the demands of their work activities (Meyer, Rowan, 1977, p. 341) (...) Rationalized formal structures arise in two contexts. First, the demands of local relational networks encourage the development of structures that coordinate and control activities (...) Second, the interconnectedness of societal relations, the collective organization of society, and the leadership of organizational elites create a highly institutionalized context" (Ibidem, p. 353).

The above outlined perspectives represent just a first step on the way of confronting various models and theories in recognizing science understanding and its functionalities. The prominent question is related to functioning science in the democratic context, how to practically effectively build science, how to provide a successful institutional context to find a compromise between openness and bureaucracy, democracy and safeguarding processes, ethos and diverse and interest-based institutional environment. Furthermore if science is more (dis)functioning and uncertain then to what extent situatedness constitutes an adequate response to provide a reliable post-research method and to what degree Meyer and Rowan are right in claiming that structures (of science) are more about myths. At this point institutionalized organization theory meets with the Mertonian postulate of science rooted socially and culturally and his justification to evoke the sociology of science to (re)discover science.

\section{REFERENCES}

[1] Berger, J. (2000). Theory and Formalization: Some Reflections on Experience. Sociological Theory, $18(3), 482-489$.

[2] Cisbani, V. (2010). Research Methods: the Debate on Grounded Theory, Formamente - Anno V, $3 / 4,267-271$.

[3] Clarke, A.E. (2003). Situational Analyses: Grounded Theory Mapping after the Postmodern Turn. Symbolic Interaction, 4, 553 - 576.

[4] Durant, D. (2011). Models of democracy in social studies of science. Social Studies of Science, 41(5), $691-714$.

[5] Fecher, B., S. Friesike (2014). Open Science: One Term, Five Schools of Thought. In: S. Bartling, S. Friesike (eds.), Opening Science, New York: Springer International Publishing, 17 - 47.

[6] Goban-Klas, T. (1999). Media i komunikowanie masowe [Media and mass communication], Warsaw: PWN, 91 - 92.

[7] Jedlikowska, D.(2015), What Model of Science? Towards a Sociologically Oriented Science Policy. Journal of Education Culture and Society, 1, 43 - 53.

[8] Kacperczyk, A. (2007). Badacz i jego poszukiwania w świetle "Analizy sytuacyjnej" Adele E. Clarke [Researcher and his/her investigations in the light of Adele E. Clarke's "Situational Analysis"]. Przegląd Socjologii Jakościowej, 3(2), 5 - 32. 
[9] Merton, R. (1973). The Sociology of Science. Theoretical and Empirical Investigations. Chicago, London: The University of Chicago Press.

[10] Meyer, J.W., B. Rowan (1977). Institutionalized Organizations: Formal Structure as Myth and Ceremony, American Journal of Sociology, 83(2), 340 - 363.

[11] Liberatore, A., S. Funtowicz (2003). 'Democratizing' expertise, 'expertising' democracy: what does this mean and why bother?. Science and Public Policy, 30(3), 146 - 150.

[12] Logar, N. (2011). Scholarly science policy models and real policy, RSD for SciSIP in US Mission Agencies. Policy Sciences, 44(3), 249 - 266.

[13] Sztompka, P. (2007). Trust in Science. Robert K. Merton's Inspirations. Jounral of Classical Sociology, 7(2), $211-220$.

[14] Turnpenny, J., Jones, M., Lorenzoni, I. (2011). Where Now for Post-Normal Science?: A Critical Review of its Development, Definitions and Uses. Science, Technology \& Human Values, 36(3), $287-306$.

[15] Valente, A., Castellani, T., Larsen, M., Aro, A.R. (2014). Models and visions of science - policy interaction: remarks from Delphi study in Italy. Science and Public Policy, 1 - 14. 